\title{
Synthesis of Styrene and Cyclopentadiene (Co)oligomers on the Basis of Fraction C9 of Oil Refining By-products
}

\author{
Roman Subtelnyi, Oksana Orobchuk, Bohdan Dzinyak \\ Department of Technology of Organic Products, Lviv Polytechnic National University, UKRAINE, Lviv, S. \\ Bandery street 12, E-mail: roman.o.subtelnyi@lpnu.ua, or_oksana@ukr.net
}

\begin{abstract}
The production of styrenic and cyclopentadiene co-oligomers by oil refining by-products (hydrocarbon fraction C9) oligomerization studied. The combination of methods of low temperature suspension oligomerization and post-(co)oligomerization of unreacted hydrocarbons allow to obtain, on the basis of the hydrocarbon fraction $\mathrm{C} 9$, the styrenic and cyclopentadiene (co)oligomers, which differ in their properties and applications.
\end{abstract}

Keywords - liquid pyrolysis products, suspension (co)oligomerization, hydrocarbon fraction C9, cyclopentadiene, styrene.

\section{Introduction}

A significant amount (about 30\%) of liquid by-products of pyrolysis (LBP) is formed at petroleum products pyrolysis (e.g. diesel fuel). Based on LBP hydrocarbon fraction C9 respectively, are obtained aromatic oligomers (so-called petroleum resins). They have a wide range of applications as film forming agents in lacquer-paint and anticorrosive coatings $[1,2]$.

The low-temperature suspension oligomerization can reduce the temperature and duration of the process compared to the existing technologies. Due to the low temperature of the process, the styrene monomers and their derivatives are introduced into the reaction. The resulting hydrocarbon resin is a styrenic (co)oligomer and is characterized by a low color index. Dicyclopentadiene (DCPD) is inactive in radical polymerization reactions. Cyclopentadiene (CPD) is polymerized by free radical mechanism. A cycle is revealed (monomerization) of the DCPD at temperatures 453-463 $\mathrm{K}$ with the formation of two reactive CPD monomers, by retrodyenic reaction Diels-Alder synthesis $[3,4]$.

We proposed a two-stage method (Fig.1) for the synthesis of (co)oligomers of styrene and cyclopentadiene [5]:
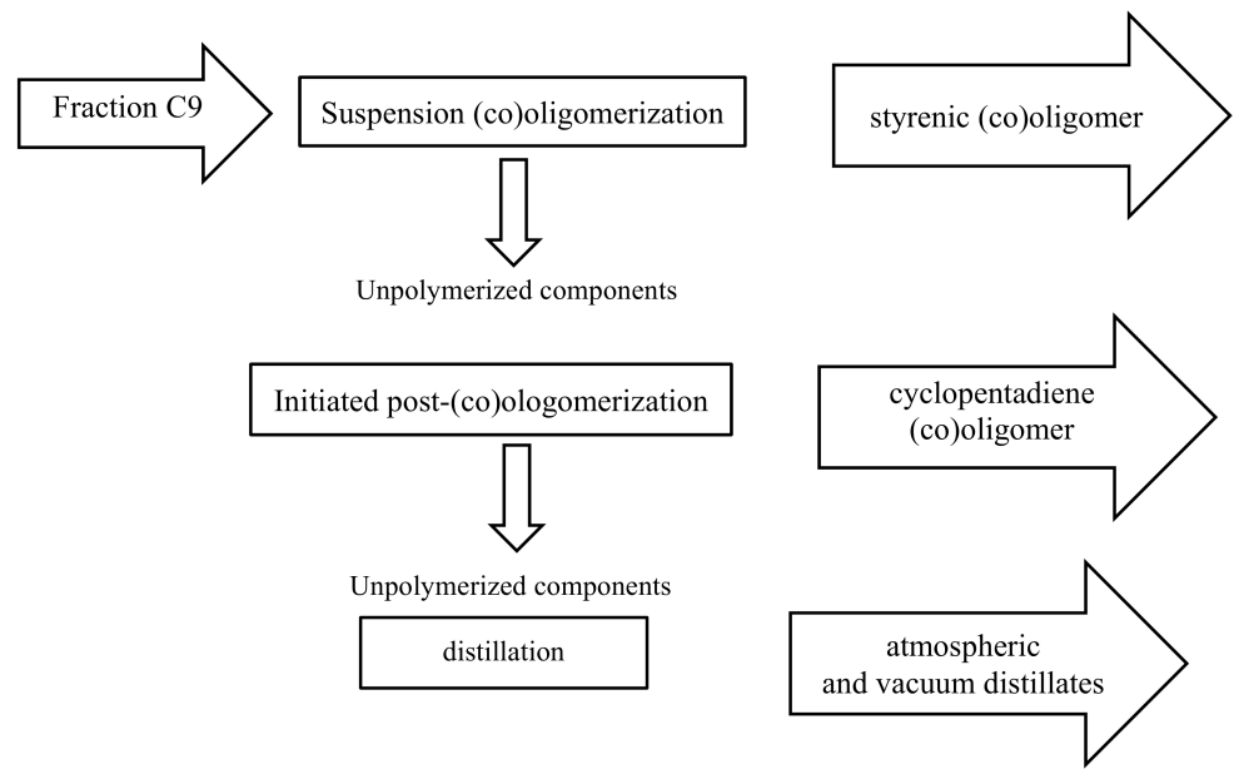

Fig.1. Two-stage method for the synthesis of co-oligomers of styrene and cyclopentadiene 
- the first stage - low-temperature (303-353 K) suspension or emulsion cooligomerization of fraction C9 hydrocarbons. At this stage, a styrenic (co)oligomer is obtained.

- the second stage is the thermal or initiated post-cooligomerization of unreacted hydrocarbons from the first stage. The temperature of the process is $453-473 \mathrm{~K}$. At this stage, a cyclopentadiene (co)oligomer with a small number of parts of other unsaturated hydrocarbons of the $\mathrm{C} 9$ fraction is obtained.

\section{Experimental Results and Discussion}

Composition of the reaction mixture of suspension oligomerization:

- the dispersion medium - water;

- the disperse phase - liquid pirolisis by-products fraction C9 (density - $936 \mathrm{~kg} / \mathrm{m}^{3}$; bromine number $-68 \mathrm{~g} \mathrm{Br}_{2} / 100 \mathrm{~g}$, molecular weight -102 , the content of unsaturated compounds to $45 \%$ wt. especially: styrene - 17,85 \% viniltoluene - 6,99\%, dicyclopentadiene - 18,00\%, indene $1,25 \%$.);

- the initiator is soluble in the disperse phase (1,0\%wt. calculated on the C9 fraction);

- suspension stabilizer - polyvinyl alcohol (0,1 \%wt. calculated on the dispersion medium).

The suspension oligomerization of the $\mathrm{C} 9$ fraction was carried out in a three-necked flask equipped with a rotary stirrer. The resulting mixture was separated by centrifuge $(4000 \mathrm{rpm})$.

Post-(co)oligomerization was carried out in thermostatically controlled sleeves at a temperature of $453 \mathrm{~K}$ for 6 hours, with the addition of a suitable initiator in an amount of $1.0 \%$ by weight. The choice of temperature is due to the composition of the fraction, namely the presence of a significant amount of dicyclopentadiene (about $13.6 \%$ by weight, calculated on the initial fraction) and its homologues. Unreacted hydrocarbons were isolated by atmospheric and vacuum distillation.

For the obtained (co)oligomers yield (calculated on the $\mathrm{C}_{9}$ fraction), unsaturation (bromine number), color index by iodometric scale, softening temperature and average molecular weight were determined. The results are shown in Table. 1.

Suspension (co)oligomerization of unsaturated hydrocarbons of C9 fraction (first stage) ensures maximum yield of the product - up to $19.0 \%$ by weight (calculated on the $\mathrm{C}_{9}$ fraction). Chromatographic analysis revealed that at first stage, the styrene monomers and its derivatives (vinyltoluene, methylstyrene) are introduced into the cooligomerization reaction. In the reaction mixture remaining after the separation of the (co)oligomer and distillation of the precipitant there are high-boiling reactive dicyclopentadiene, indene, residual styrene and its derivatives.

As a result of initiated high-temperature post-(co)coligomerization of unreacted residues (second stage) was obtained hydrocarbon resins with a high content of cyclopentadiene units. The cyclopentadiene (co)oligomer contains insignificant quantities of styrene and vinyl-toluene units that did not react at the first stage of the process.

The cyclopentadiene (co)oligomers obtained at the second stage is characterized by a lower index of unsaturation (22,2 - 27,8 $\mathrm{g} \mathrm{Br}_{2} / 100 \mathrm{~g}$ ), a similiar softening temperature (350-358 K), a higher average molecular weight $(640$ - 700) and a significantly higher color index - 60 ... 80 $\mathrm{mg} \mathrm{I}_{2} / 100 \mathrm{ml}$ (compared to styrenic (co)oligomers).

The composition of the (co)oligomers was determined basing on the data of the IRspectroscopic analysis of the (co)oligomers samples of and the chromatographic analyzes of the C9 fraction and distillates. 
Table 1

Yield, physical and chemical properties of (co)oligomers

\begin{tabular}{|c|c|c|c|}
\hline \multirow[b]{2}{*}{ Characteristics } & \multicolumn{3}{|c|}{ Initiator } \\
\hline & $\begin{array}{l}\text { Benzoyl } \\
\text { Peroxide }\end{array}$ & $\begin{array}{c}\text { tert-Butyl } \\
\text { Hydroperoxide }\end{array}$ & $\begin{array}{l}\text { Cumyl } \\
\text { Hydroperoxide }\end{array}$ \\
\hline \multicolumn{4}{|c|}{$\begin{array}{c}\text { Suspension (co)oligomerization } \\
\left([\text { fraction } C 9]:[\text { water }]=1: 2 ; \mathrm{T}=353 \mathrm{~K} ; \tau=3 \text { hours; } \mathrm{C}_{\text {initiator }}=1,0 \% \mathrm{wt} . ; \mathrm{C}_{\text {stabilizer }}=0,1 \% \mathrm{wt} .\right)\end{array}$} \\
\hline $\begin{array}{l}\text { Styrene (co)oligomer yield, \% by weight } \\
\text { (calculated on the C9 fraction) }\end{array}$ & 19,0 & 9,8 & 16,0 \\
\hline Bromine number, $\mathrm{g} \mathrm{Br}_{2} / 100 \mathrm{~g}$ & 30,3 & 32,0 & 19.9 \\
\hline Softening point, $\mathrm{K}$ & 354 & 340 & 350 \\
\hline Molecular weight (cryoscopy) & 495 & 460 & 490 \\
\hline Color by iodometric scale, $\mathrm{mg}_{2} / 100 \mathrm{ml}$ & 20 & 30 & 30 \\
\hline \multicolumn{4}{|c|}{ Post-co-oligomerization $\left(\mathrm{C}_{\text {initiator }}=1,0 \% \mathrm{wt} ., \mathrm{T}=453 \mathrm{~K}, \tau=6\right.$ hours $)$} \\
\hline $\begin{array}{l}\text { Cyclopentadiene (co)oligomer yield, \% by weight } \\
\text { (calculated on the C9 fraction) }\end{array}$ & 19,8 & 30,1 & 25,7 \\
\hline Bromine number, $\mathrm{g} \mathrm{Br}_{2} / 100 \mathrm{~g}$ & 20,4 & 22,8 & 23,4 \\
\hline Softening point, $\mathrm{K}$ & 358 & 354 & 350 \\
\hline Molecular weight (cryoscopy) & 700 & 640 & 670 \\
\hline Color by iodometric scale, $\mathrm{mg}_{2} / 100 \mathrm{ml}$ & 80 & 80 & 80 \\
\hline Total yield, \% wt. (calculated on the C9 fraction) & 38,8 & 39,9 & 41,7 \\
\hline
\end{tabular}

\section{Conclusion}

The possibility of synthesis of styrenic and cyclopentadiene co-oligomers by two-stage method of oil refining by-products (hydrocarbon fraction C9) oligomerization was established. The two-stage method of the C9 fraction oligomerization allows to obtaine two types of oligomers with different physical and chemical characteristics. The total yield of oligomers is higher than with one-stage initiated high-temperature oligomerization.

\section{References}

[1] V. H. Bondaletov, L. Y. Bondaletova, and N. V. Tkhan, "Ispolzovanye zhydkykh produktov pyrolyza uhlevodorodnoho syria v synteze neftepolymernykh smol," Uspekhy sovremennoho estestvoznanyia, vol. 1, no. 7, pp. 1130-1133, 2015.

[2] R. Mildenberg, M. Zander, and G. Collin, Hydrocarbon resins. New York, USA: VCH Publishers. Inc, 1998.

[3] Z. Xiong, Z. Mi, and X. Zhang, "Study on the oligomerization of cyclopentadiene and dicyclopentadiene to tricyclopentadiene through Diels-Alder reaction," Reaction Kinetics and Catalysis Letters, vol. 85, pp. 89-97, 2005.

[4] J. Hou, D. Zhang, R. Lin, S. Wang, and W. H. Sun, "Copolymerization of cyclopentadiene with styrene by methylaluminoxane catalyst," Polymers for Advanced Technologies, vol. 17, pp. 486-490, 2006.

[5] O. M. Orobchuk, R. O. Subtelnyi, Z. I. Maresh, and B. O. Dziniak, "Dvostadiinyi sposib initsiiovanoi koolihomeryzatsii nenasychenykh vuhlevodniv fraktsii C9," Visnyk Natsionalnoho universytetu „Lvivska politekhnika”. Khimiia, tekhnolohiia rechovyn ta yikh zastosuvannia, vol. 787, pp. 154-159, 2014. 